\title{
The Changing Clinical Landscape in Acupuncture for Women's Health: A Cross-Sectional Online Survey in New Zealand and Australia
}

\author{
Sandro Graca \\ Northern College of Acupuncture \\ Debra Betts \\ NICM Health Research Institute, Western Sydney University \\ Caroline A. Smith \\ NICM Health Research Institute, Western Sydney University \\ Mike Armour ( $\nabla$ m.armour@westernsydney.edu.au ) \\ NICM Health Research Institute, Western Sydney University \\ Kate Roberts \\ NICM Health Research Institute, Western Sydney University
}

\section{Research Article}

Keywords: Acupuncture, Chinese medicine, women's health, clinical practice, research literacy

Posted Date: September 9th, 2021

DOI: https://doi.org/10.21203/rs.3.rs-869442/v1

License: (c) (7) This work is licensed under a Creative Commons Attribution 4.0 International License. Read Full License

Version of Record: A version of this preprint was published at BMC Complementary Medicine and Therapies on March 31st, 2022. See the published version at https://doi.org/10.1186/s12906-022-03576-3. 


\section{Abstract \\ Background}

Acupuncture is growing in popularity as a treatment option for women's health worldwide with reported increasing usage in the last ten years. A significant number of clinical trials and meta-analysis are now published on aspects of women's health treatment with acupuncture. The aim of this survey was to explore if, how and why, aspects of acupuncture practice has changed since our last survey in 2013.

\section{Method}

An online cross-sectional survey of registered acupuncturists and Chinese Medicine practitioners in Australia and New Zealand. Questions covered the practitioner demographics and training, women's health conditions commonly treated, modalities used, sources of information and continuing education (CE) (e.g. webinars), changes in clinical practice, and referral networks.

\section{Results}

One hundred and seventy registered practitioners responded to this survey, with $93 \%$ reporting treating women's health in the last 12 months. The majority of respondents were from Australia (60\%), held a bachelors level qualification (60\%), and used a traditional Chinese medicine framework (86\%). Most practitioners incorporated other modalities in addition to acupuncture. Most practitioners' referral networks were predominantly based on word of mouth for menstrual, fertility and pregnancy related conditions, with referrals from medical practitioners being much less common. More than half (57\%) reported having changed their women's health practice in the past 12 months; just over a quarter of those who changed treatment (27\%) reported it was due to research findings. The most commonly used sources of information/CE used to inform treatment were webinars and conferences, while peer-reviewed journal articles were the least commonly used source.

\section{Conclusion}

Acupuncture practitioners in Australia and New Zealand commonly treat women's health conditions, but this is usually the result of women seeking them out, rather than being referred from a medical practitioner. The majority of practitioners did report changing their women's health practice, but peer reviewed academic articles alone are not an ideal medium to convey this information since practitioners favour knowledge obtained from webinars and conferences. Academics and other clinician researchers should consider alternative means of disseminating knowledge beyond traditional academic publications and conferences, special interest groups may assist in this and also help improve research literacy.

\section{Background}

Acupuncture is one of the most commonly used traditional, complementary, alternative or integrative medicine therapies (TCAIM) in Australia [1] and New Zealand [2], and worldwide there are reports of increasing rates of acupuncture usage in the USA [3], UK [4], and the EU [5]. Since our previous survey on acupuncture usage for women's health in 2014 [6] there have been a number of clinical trials and meta-analysis exploring the effectiveness of acupuncture in women's health conditions, with some studies showing positive results, while others show a lack of evidence for efficacy [7-11]. Both positive and negative findings generated significant coverage and discussion on both social media and more traditional media [12, 13] which may have changed presentation rates for various conditions, as well as referral rates from other medical professionals. Given that patients decision to use acupuncture is not driven by evidence of efficacy as much as they are by recommendations from friends and family $[14,15]$, it is unclear if these findings, even when in the lay media, have altered rates of clinical presentation for women's health conditions.

Previous research from the early to mid 2000s had shown that clinical trial results do not always change practice for acupuncture practitioners [16, 17]. Findings from our group's recent research revealed that acupuncturists treating women's health conditions perceived the lack of individualization of treatments in trial designs as a barrier to incorporating research findings into their practice [18]. Changes in Chinese medicine education programs [19, 20], and an interest in designing and implementing an evidence based practice curriculum [21] may have altered practitioners interest and ability to change practice to reflect the current evidence. A growing interest in post-graduate fertility training and certification [22], along with specialist organizations focusing on acupuncture research [23], its dissemination [24], and specialisation in acupuncture for fertility [15] and during pregnancy [25], may have also increased awareness and willingness to move towards a research-informed practice.

Given these potential developments, this study aimed to explore whether there have been significant changes since our last survey in 2013 on presentation rates to clinics by the public, referral patterns, what sources of information practitioners use to inform their practice, if they are implementing any changes in their practice, and what factors may be driving these changes.

\section{Methods Ethical approval}

was obtained from Western Sydney University Human Ethics Committee (H13099-approved 5 February 2019). An online survey was developed and hosted on the Qualtrics platform. 


\section{Participants}

Invitations to participate in the survey were distributed via social media and/or email between March 2019 and May 2019 via professional organizations in New Zealand or Australia representing acupuncture and Chinese medicine including Acupuncture NZ, New Zealand Acupuncture Standards Authority (NZASA), Australian Acupuncture and Chinese Medicine Association (AACMA) and the Australian Traditional-Medicine Society (ATMS). Participants were eligible if they were currently living in New Zealand or Australia, aged over 18, either a current member of Acupuncture NZ or NZASA (if located in New Zealand) or hold current Chinese Medicine Practitioner registration with the Australian Health Practitioner Regulation Agency (AHPRA) (if located in Australia). The survey was anonymous and there was no direct contact between the researchers and respondents themselves.

\section{Survey design}

The content of the survey was modelled on our previous 2013 survey [6] and questions covered the practitioner demographics and training, women's health conditions commonly treated, modalities used, sources of information/CE (e.g. webinars), changes in clinical practice, and referral networks.

\section{Data Analysis}

Data was analysed using Microsoft Excel or SPSS v27. Descriptive statistics were reported as means and standard deviations, or numbers and percentages, $95 \%$ confidence intervals were reported where appropriate. Between group comparisons were undertaken using the Chi-square test. Significance was set at $p<$ 0.05. Missing data was not replaced.

For the open-ended question relating to reasons for change a qualitative descriptive approach was used to analyse and code the data [26]. A qualitative content analysis was undertaken [27]. Initial meaning units were condensed into codes by one researcher (SG). Codes with similar patterns were grouped into categories. This process and the subsequent categorization were discussed with the senior author (MA).

\section{Results}

One hundred and seventy registered practitioners responded to this survey, with $93 \%$ reporting treating women's health in the last 12 months. Demographically, the majority of the respondents were female (76\%), aged between $35-44$ years-old (36\%), and practicing in Australia (60\%). Most practitioners trained in Australia, held a Bachelor's level $(60 \%)$ or Master's level qualification (21\%), with ten or more years of clinical experience (65\%). The traditional Chinese medicine (TCM) framework was the most commonly reported style of acupuncture used (86\%) and most practitioners offered other modalities in addition to acupuncture, such as moxibustion, cupping, Chinese herbal medicine, and dietary or nutritional supplements. Table 1 outlines the demographics of respondents. 
Table 1

Demographics and practice characteristics of respondents

\begin{tabular}{|c|c|c|c|c|c|c|c|c|c|c|c|c|}
\hline & \multicolumn{5}{|c|}{ Australia $(n=102)$} & \multicolumn{5}{|c|}{ New Zealand $(n=68)$} & \multicolumn{2}{|c|}{ Total $(n=170)$} \\
\hline & $\mathrm{n}$ & $(\%)$ & $95 \% \mathrm{Cl}$ & & & $\mathrm{n}$ & (\%) & $95 \% \mathrm{Cl}$ & & & $\mathrm{n}$ & $(\%)$ \\
\hline \multicolumn{13}{|l|}{ Gender } \\
\hline Male & 20 & (19.6\%) & 13.0 & - & 28.4 & 19 & (27.9\%) & 18.6 & - & 39.6 & 39 & (22.9\%) \\
\hline Female & 82 & (80.4\%) & 71.6 & - & 87.0 & 48 & (70.6\%) & 58.8 & - & 80.1 & 130 & (76.5\%) \\
\hline Other & & & & & & 1 & (1.5\%) & $<0.01$ & - & 8.6 & 1 & $(0.6 \%)$ \\
\hline \multicolumn{13}{|l|}{ Age } \\
\hline $18-25$ & 1 & $(1.0 \%)$ & $<0.01$ & - & 5.9 & 1 & $(1.5 \%)$ & $<0.01$ & - & 8.6 & 2 & $(1.2 \%)$ \\
\hline $26-34$ & 8 & (7.8\%) & 3.8 & - & 14.9 & 7 & (10.3\%) & 4.8 & - & 20.0 & 15 & $(8.8 \%)$ \\
\hline $35-44$ & 37 & (36.3\%) & 27.6 & - & 46.0 & 24 & (35.3\%) & 25.0 & - & 47.2 & 61 & (35.9\%) \\
\hline $45-54$ & 29 & (28.4\%) & 20.6 & - & 37.9 & 18 & (26.5\%) & 17.4 & - & 38.1 & 47 & $(27.6 \%)$ \\
\hline $55-64$ & 22 & $(21.6 \%)$ & 14.6 & - & 30.6 & 15 & $(22.1 \%)$ & 13.7 & - & 33.4 & 37 & $(21.8 \%)$ \\
\hline $65+$ & 5 & $(4.9 \%)$ & 1.8 & - & 11.3 & 3 & $(4.4 \%)$ & 1.0 & - & 12.7 & 8 & $(4.7 \%)$ \\
\hline \multicolumn{13}{|l|}{ Practice location } \\
\hline Australia & & & & & & & & & & & 102 & $(60.0 \%)$ \\
\hline New Zealand & & & & & & & & & & & 68 & $(40.0 \%)$ \\
\hline \multicolumn{13}{|l|}{ Years in practice } \\
\hline Less than 1 year & 1 & $(1.0 \%)$ & $<0.01$ & - & 5.9 & 4 & $(5.9 \%)$ & 1.9 & - & 14.6 & 5 & $(2.9 \%)$ \\
\hline $1-5$ years & 16 & $(15.7 \%)$ & 9.8 & - & 24.1 & 16 & $(23.5 \%)$ & 14.9 & - & 35.0 & 32 & $(18.8 \%)$ \\
\hline $6-9$ years & 10 & $(9.8 \%)$ & 5.2 & - & 17.3 & 11 & $(16.2 \%)$ & 9.1 & - & 26.9 & 21 & $(12.4 \%)$ \\
\hline $10-20$ years & 56 & $(54.9 \%)$ & 45.2 & - & 64.2 & 28 & $(41.2 \%)$ & 30.3 & - & 53.1 & 84 & $(49.4 \%)$ \\
\hline $21+$ years & 19 & $(18.6 \%)$ & 12.2 & - & 27.4 & 9 & $(13.2 \%)$ & 6.9 & - & 23.5 & 28 & $(16.5 \%)$ \\
\hline \multicolumn{13}{|l|}{ Training location } \\
\hline New Zealand & 1 & $(1.0 \%)$ & $<0.01$ & - & 5.9 & 47 & $(69.1 \%)$ & 57.3 & - & 78.9 & 48 & $(28.2 \%)$ \\
\hline Australia & 95 & (93.1\%) & 86.3 & - & 96.9 & 5 & $(7.4 \%)$ & 2.8 & - & 16.5 & 100 & $(58.8 \%)$ \\
\hline China & 23 & $(22.5 \%)$ & 15.5 & - & 31.6 & 19 & $(27.9 \%)$ & 18.6 & - & 39.6 & 42 & $(24.7 \%)$ \\
\hline Other & 14 & $(13.7 \%)$ & 8.2 & - & 21.9 & 7 & $(10.3 \%)$ & 4.8 & - & 20.0 & 21 & $(12.4 \%)$ \\
\hline \multicolumn{13}{|l|}{ Highest qualification } \\
\hline Diploma & 11 & $(10.9 \%)$ & 6.0 & - & 18.6 & 13 & $(19.4 \%)$ & 11.6 & - & 30.6 & 24 & $(14.3 \%)$ \\
\hline Bachelor & 59 & $(58.4 \%)$ & 48.7 & - & 67.6 & 41 & $(61.2 \%)$ & 49.2 & - & 72.0 & 100 & (59.5\%) \\
\hline Master & 25 & $(24.8 \%)$ & 17.3 & - & 34.0 & 11 & $(16.4 \%)$ & 9.3 & - & 27.2 & 36 & $(21.4 \%)$ \\
\hline Doctor & 3 & $(3.0 \%)$ & 0.7 & - & 8.7 & 1 & $(1.5 \%)$ & $<0.01$ & - & 8.8 & 4 & $(2.4 \%)$ \\
\hline $\mathrm{PhD}$ & 3 & $(3.0 \%)$ & 0.7 & - & 8.7 & 1 & $(1.5 \%)$ & $<0.01$ & - & 8.8 & 4 & $(2.4 \%)$ \\
\hline \multicolumn{13}{|l|}{ Style of acupuncture } \\
\hline Five Element & 21 & $(20.6 \%)$ & 13.8 & - & 29.5 & 16 & $(23.5 \%)$ & 14.9 & - & 35.0 & 37 & $(21.8 \%)$ \\
\hline Japanese & 21 & $(20.6 \%)$ & 13.8 & - & 29.5 & 8 & $(11.8 \%)$ & 5.8 & - & 21.8 & 29 & $(17.1 \%)$ \\
\hline Traditional Chinese medicine & 84 & (82.4\%) & 73.7 & - & 88.6 & 63 & $(92.6 \%)$ & 83.5 & - & 97.2 & 147 & $(86.5 \%)$ \\
\hline Western medical acupuncture & 6 & $(5.9 \%)$ & 2.5 & - & 12.5 & 9 & $(13.2 \%)$ & 6.9 & - & 23.5 & 15 & $(8.8 \%)$ \\
\hline Other style & 18 & $(17.6 \%)$ & 11.4 & - & 26.3 & 8 & $(11.8 \%)$ & 5.8 & - & 21.8 & 26 & (15.3\%) \\
\hline \multicolumn{13}{|l|}{ Other services } \\
\hline $\begin{array}{l}\text { Microsystems acupuncture } \\
\text { (ear / scalp, etc) }\end{array}$ & 59 & $(58.4 \%)$ & 48.7 & - & 67.6 & 44 & $(64.7 \%)$ & 52.8 & - & 75.0 & 103 & (60.6\%) \\
\hline
\end{tabular}




\begin{tabular}{|c|c|c|c|c|c|c|c|c|c|c|c|c|}
\hline \multirow[b]{2}{*}{ Chinese herbal medicine } & \multicolumn{5}{|c|}{ Australia $(n=102)$} & \multicolumn{5}{|c|}{ New Zealand $(n=68)$} & \multicolumn{2}{|c|}{ Total $(n=170)$} \\
\hline & 78 & (77.2\%) & 68.1 & - & 84.4 & 47 & (69.1\%) & 57.3 & - & 78.9 & 125 & (73.5\%) \\
\hline Western herbal medicine & 14 & (13.9\%) & 8.3 & - & 22.1 & 14 & (20.6\%) & 12.6 & - & 31.8 & 28 & $(16.5 \%)$ \\
\hline Cupping & 84 & (83.2\%) & 74.6 & - & 89.3 & 58 & (85.3\%) & 74.8 & - & 92.0 & 142 & $(83.5 \%)$ \\
\hline Tuina & 40 & (39.6\%) & 30.6 & - & 49.4 & 35 & (51.5\%) & 39.8 & - & 63.0 & 75 & $(44.1 \%)$ \\
\hline Moxibustion & 89 & (88.1\%) & 80.2 & - & 93.2 & 56 & (82.4\%) & 71.5 & - & 89.8 & 145 & (85.3\%) \\
\hline Dietary / nutritional supplements & 64 & $(63.4 \%)$ & 53.6 & - & 72.1 & 39 & $(57.4 \%)$ & 45.5 & - & 68.4 & 103 & $(60.6 \%)$ \\
\hline Tai Chi / Qi Gong & 19 & $(18.8 \%)$ & 12.3 & - & 27.6 & 8 & $(11.8 \%)$ & 5.8 & - & 21.8 & 27 & $(15.9 \%)$ \\
\hline Other & 16 & $(15.8 \%)$ & 9.9 & - & 24.3 & 17 & $(25.0 \%)$ & 16.2 & - & 36.5 & 33 & $(19.4 \%)$ \\
\hline
\end{tabular}

In terms of conditions treated, $92 \%$ provided treatment for menstrual health conditions, most commonly period pain (dysmenorrhea), irregular periods, polycystic ovary syndrome (PCOS) and menstrual headaches. Once per week was the most common treatment frequency (75\%), with only $10 \%$ treating twice per week or more. Seventy-six percent of respondents treated fertility related conditions, most commonly in women, for a variety of reasons including general fertility health and in conjunction with in-vitro fertilisation / assisted reproductive technology, with a minority of respondents (9\%) reporting treating men for fertility issues. Eighty-five percent of respondents reported treating a wide range of pregnancy related conditions, most commonly nausea in pregnancy, back/hip or pelvic pain, breech presentation and pre-birth preparation.

\section{Referral networks:}

Most practitioners' referral networks were predominantly based on word of mouth for menstrual, fertility and pregnancy related conditions. Despite $41 \%$ reporting working in conjunction with biomedical clinicians when treating menstrual conditions, this does not translate into a higher number of referrals to practitioners for menstrual issues $(n=46,32.3 \%)$ when compared to fertility $(n=59,46.1 \%)$ or pregnancy $(n=82,59.4 \%)$. Nevertheless, the number of referrals from other medical practitioners is higher than the number of referrals from other complementary and alternative medicine (CAM) providers, especially for fertility $(n=82,64.1 \%)$ and pregnancy $(n=88,63.7 \%)$. The reported higher prevalence of acupuncturists working in conjunction with other CAM providers when treating menstrual conditions (58\%) correlates with a higher number of referrals they receive from this group of practitioners ( $n=77,54 \%$ ). Table 2 outlines the referral patterns by condition treated.

Table 2

Referral patterns by condition treated

\begin{tabular}{|lllllll|}
\hline Condition & \multicolumn{2}{l}{ Menstrual } & \multicolumn{2}{l|}{ Fertility } & \multicolumn{2}{l|}{ Pregnancy } \\
& \multicolumn{2}{l}{$\mathbf{n = 1 4 2}$} & \multicolumn{2}{l|}{$\mathbf{n = 1 2 8}$} & \multicolumn{2}{c|}{$\mathbf{n = 1 3 8}$} \\
\hline & $\mathrm{n}$ & $(\%)$ & $\mathrm{n}$ & $(\%)$ & $\mathrm{n}$ & $(\%)$ \\
\hline Word of mouth & 142 & $(100 \%)$ & 128 & $(100 \%)$ & 138 & $(100 \%)$ \\
\hline Referral from other CAM providers & 77 & $(54.0 \%)$ & 82 & $(64.1 \%)$ & 88 & $(63.7 \%)$ \\
\hline Referral from medical health practitioners & 46 & $(32.3 \%)$ & 59 & $(46.1 \%)$ & 82 & $(59.4 \%)$ \\
\hline Advertising / website promotion & 76 & $(53.5 \%)$ & 69 & $(53.9 \%)$ & 76 & $(55.1 \%)$ \\
\hline
\end{tabular}

One third of the respondents do not work with any other associate practitioner when treating menstrual conditions. Moreover, when treating fertility, most respondents $(60 \%)$ work isolated from other fertility practitioners, with only $6 \%$ working onsite at a fertility clinic, while $29 \%$ of practitioners work from their own clinic, albeit closely with fertility specialists.

\section{Changes in practice and sources of knowledge}

Over half (57\%) of the participants reported having changed their women's health practice in the past 12 months, mostly changes in their treatments (53\%), with just over a quarter of those who changed treatment (27\%) reporting it was due to research findings. The most used sources of information the practitioners relied on to inform their treatments were webinars and conferences, while peer-reviewed journal articles were the least commonly used source. Table 3 reports on the reasons for change of treatment, broken down by practice and demographics. 
Table 3

Reasons for the change in the treatment of women's health

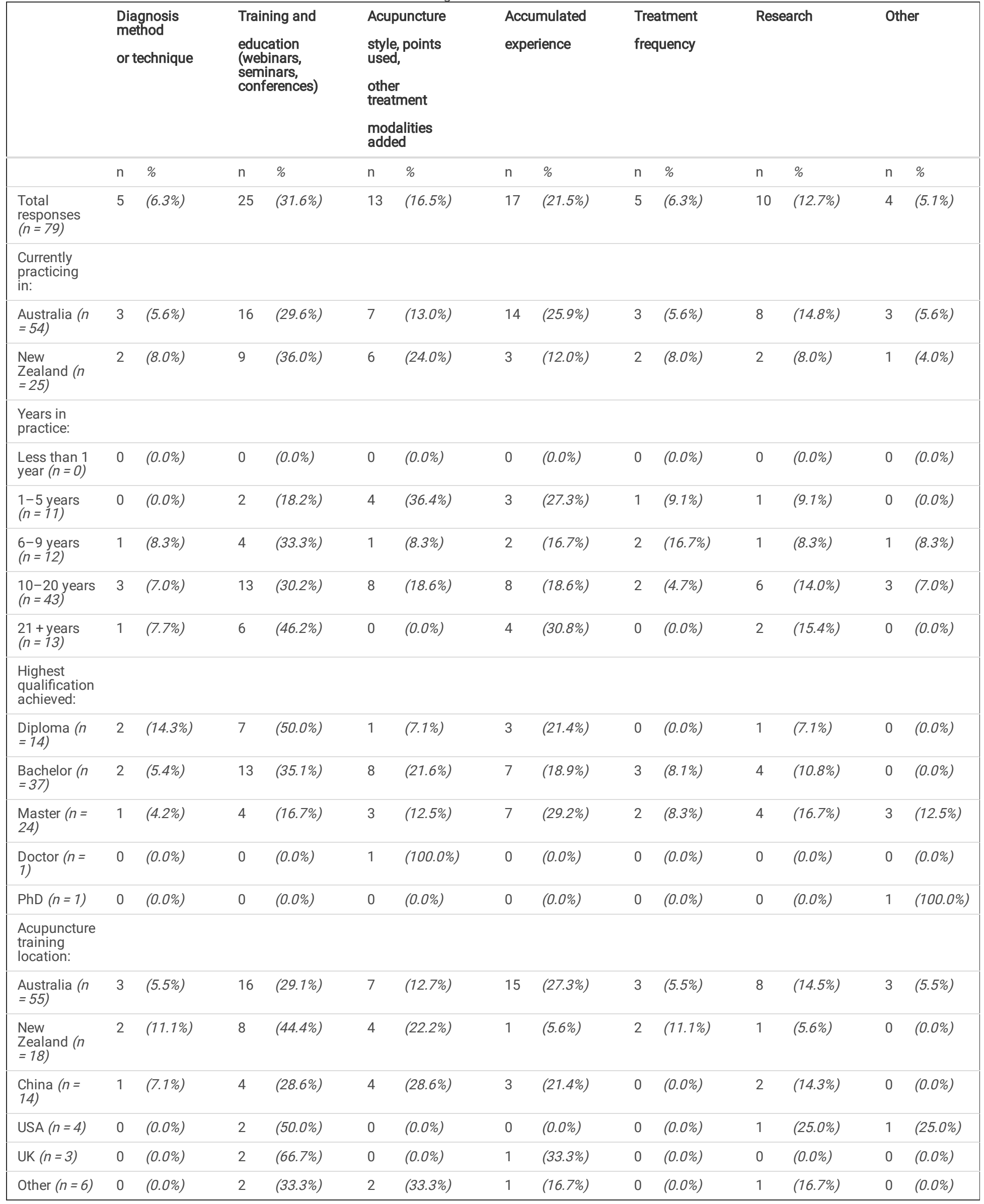


Exploring demographic and practice factors that may have influenced the decision to change treatment, there was no significant effect of where the acupuncture training was undertaken $(p=0.987)$, number of years in practice $(p=0.178)$, the highest qualification achieved $(p=0.51)$, or if they had undertaken postgraduate study $(p=0.131)$.

\section{Discussion}

We found that the use of peer reviewed research was the least used source of knowledge and not a major agent of change for acupuncture practitioners, which explains why very few changed their practice due to research alone, despite a substantial increase in the number of clinical trials and improvements in reporting quality of acupuncture publications over time [28-30]. Birch and colleagues [31] found a total of 1311 publications between $1991-2017$ with recommendations for the use of acupuncture, especially in North America, Europe, and Australasia, made by government health institutions, national guideline, and medical specialty groups [31] but noted that that not all these recommendations are known within the acupuncture or the mainstream medical communities [31,32] and identified the need to address the lack of presentations focusing on research and implementation at international symposia [32]. A recent analysis supports this lack of awareness, with a recent analysis on Australian guidelines in pregnancy showing significant inconsistences in the recommendation, or in some cases prohibition, of acupuncture for various conditions including nausea and vomiting, and pelvic pain [33].

Sixty-five percent of our respondents have ten or more years of experience in practice and hold bachelor's level (60\%) or master's level (21\%) qualification, in line with previous findings that $78 \%$ of Chinese medicine practitioners in Australia hold a bachelor's degree or higher [34]. Despite a substantial minority holding post graduate degrees, this did not necessarily make them more likely to use research in their practice. Our findings also suggest that despite being experienced practitioners, those with more than 10 years' experience are just as likely as newer graduates to change their practice. Our study found that irrespective of qualification and length of time in practice, webinars, seminars, and presentations by experts were key in shaping the acupuncture practice for Australian and New Zealand practitioners. These findings support our team's qualitative work [18] on the importance of academic and/or clinician researchers ensuring they are not only publishing within the academy but ensuring they use reputable webinars, seminars, and conferences to reach their clinical peers, to ensure translation of research into clinical practice. Similarly, in the field of naturopathy, the role and relevance of conferences and professional events to inform clinical practice was recently highlighted by Steel and colleagues [35] who reported that naturopathic practitioners use those almost as often as scientific journals, which are their main source of knowledge to inform their clinical practice [35]. Promoting the engagement of practitioners in generating practice-based knowledge through the publication of their case studies [18] and of researchers in supporting the translation of their findings into clinical decision-making offers a solid foundation for evidence-based practice. Furthermore, research literacy and knowledge translation skills can also help practitioners to translate evidence and generate content to share on social media and inform prospective patients and the general public [35].

Previous findings from a survey of TCM practitioners in the U.K. showed that education was seen as necessary to ensure that practitioners stay updated with the medical developments in the fertility field and more than half of the respondents had taken post-qualification training in acupuncture for fertility [22]. Despite this, respondents' opinions varied on whether the specialized training is essential, while others suggested that overspecialization could impact the holistic nature of the treatment [22]. While there are special interest groups for women's health in Australia, New Zealand [36, 37], and the U.K. [38] thus far only North America has an organization examining and registering TCM practitioners specializing in reproductive medicine [39] and one dedicated to obstetrical acupuncture [25]. These organizations started in the USA and Canada respectively, and although most of the members are from North America, both have recently opened their examination process to practitioners worldwide, providing the applicants meet the required standards, including the continuing education units necessary to sit the exam. Engaging practitioners with organisations such as this may result in improvements in research literacy while also enabling them to contribute with new knowledge from the coalface to better reflect the complexity of acupuncture practice and inform research design accordingly [18, 40]. The two-way avenue of translation of research into practice and vice-versa includes benefits to both the profession and to the public.

Our study found that acupuncturists still treat a wide range of women's health conditions, and that most of their referrals, especially for menstrual health, come from word of mouth, while for there are a greater proportion of referrals from biomedical practitioners when treating fertility and pregnancy. However overall, the rate of referrals from medical practitioners remains relatively low overall, and it is unclear from our survey if these are formal inter-professional referrals or a less formal 'it cannot hurt to try' endorsement. The low medical referral rate may be partly due to a recently identified gap in knowledge by medical practitioners about the availability, provision, and efficacy of acupuncture, leading to less patient referrals to CAM providers [41]. Previously identified communication barriers between patients using CAM and not disclosing it to their healthcare providers [41, 42] may also contribute to this. The dynamics of this communication barrier are self-perpetuated by patients refraining from initiating the disclosure of using CAM treatments due to their expectation that a non-judgemental conversation will be initiated by their primary care clinician, whilst the latter interprets the low levels of report as low levels of use of acupuncture and other CAM modalities by their patients [42]. These factors may contribute towards acupuncturists reporting working in relative isolation from other medical practitioners. Recent calls for greater patient-centred collaborative and integrative models [43] can potentially address previously identified barriers such as the dominance of the biomedical paradigm [44] and some clinicians' uncertainty regarding CAM practitioners' scope of practice [45]. Despite concerns on the scientific evidence, professional regulation and safety, New Zealand healthcare professionals have a positive attitude towards CAM, with midwives recommending CAM and GPs referring patients to acupuncture [2, 46]. Patient-reported data from a maternity acupuncture service in New Zealand shows that acupuncture offers a safe and beneficial non-pharmacological treatment option for pregnant women with lumbopelvic pain [47, 48]. A recent review of RCTs on the use of acupuncture or acupressure in helping women to manage pain during labour revealed that acupuncture may increase satisfaction with pain management and reduce the use of pharmacological analgesia, while acupressure may reduce pain intensity [49]. In Australia, a program of antenatal education based on complementary therapies for labour and birth demonstrated a reduction of use of hospital resources, which could decrease birth-related healthcare costs by approximately $9 \%$ [50].

There are several important limitations to acknowledge. Firstly, like other practitioner surveys of acupuncturists in Australasia, our overall response rate was low $[6,51]$. This is likely due to several factors, primarily that those who were not interested in women's health were unlikely to fill in the survey, and secondly, due to the low priority that practitioners put on research they may not feel inclined to engage with researchers [18]. Therefore, caution must be taken in 
extrapolating our findings, however our key findings of lack of engagement with research are in line with previous work, both quantitively [51] and qualitatively [18]. Secondly, we did not request detailed information regarding the referral interactions with other practitioners. Referral patterns both to and from acupuncture, and other forms of CAM, is a grey area as many 'referrals', are not recorded within medical records, and are rather verbal endorsements and often to a modality rather than a specific practitioner, therefore it is likely that these referral interactions are different to those between medical doctors [52].

\section{Conclusion}

Acupuncture practitioners in Australia and New Zealand commonly treat women's health conditions, but this is usually the result of women seeking them out rather than being referred from a medical practitioner. The majority of practitioners did report changing their women's health practice, but peer reviewed academic articles alone are not an ideal medium to convey this information since practitioners favour knowledge obtained from webinars and conferences. Academics and other clinician researchers should consider alternative means of disseminating knowledge beyond traditional academic publications and conferences, and special interest groups may assist in this and also help improve research literacy.

\section{List Of Abbreviations}

AACMA - Australian Acupuncture and Chinese Medicine Association (AACMA)

Acupuncture NZ - Acupuncture New Zealand

ATMS - Australian Traditional-Medicine Society

CAM - Complementary and alternative medicine

GPs - General practitioners

NZASA - New Zealand Acupuncture Standards Authority (NZASA)

PCOS - Polycystic ovary syndrome

RCTs - Randomised controlled trials

TCAIM - Traditional, complementary, alternative or integrative medicine therapies

TCM - Traditional Chinese medicine

\section{Declarations}

Ethics approval: Ethical approval was obtained from Western Sydney University Human Ethics Committee (H13099-approved 5 February 2019). Informed consent was gained prior to participants completing the survey.

Consent for publication: Not applicable

Conflict of interest: As a medical research institute, NICM Health Research Institute receives research grants and donations from foundations, universities, government agencies and industry. Sponsors and donors provide untied and tied funding for work to advance the vision and mission of the Institute. This study was not specifically supported by donor or sponsor funding to NICM. MA, KR, SG and DB are qualified acupuncturists who have been in clinical practice within the last two years. SG is a board member of Evidence Based Acupuncture.

Acknowledgments: We acknowledge with appreciation the contributions of the practitioners who completed this study along with the professional bodies who supported this including Acupuncture NZ, NZASA, AACMA and ATMS.

Author contributions: Conceived and designed the study MA, DB, CS. Data collection MA. Data analysis SG, MA. Project supervision CS. Contributed to writing the manuscript; Original draft SG, MA, DB, KR. Review and editing MA, SG, DB, KR, CS. All authors approved the final manuscript.

Availability of data and material: The datasets used and/or analysed during the current study are available from the corresponding author on reasonable request.

Disclaimers: The views, opinions, findings, and conclusions or recommendations expressed in this paper are strictly those of the author(s).

Funding: No funding was received for this work.

\section{References}

1. Foley $\mathrm{H}$, Steel A, Adams J: Consultation with complementary medicine practitioners by individuals with chronic conditions: Characteristics and reasons for consultation in Australian clinical settings. Health Soc Care Community 2021, 29(1):91-103.

2. Liu L, Tang Y, Baxter GD, Yin H, Tumilty S: Complementary and alternative medicine - practice, attitudes, and knowledge among healthcare professionals in New Zealand: an integrative review. BMC Complement Med Ther 2021, 21(1):63. 
3. Cui J, Wang S, Ren J, Zhang J, Jing J: Use of acupuncture in the USA: changes over a decade (2002-2012). Acupunct Med 2017, 35(3):200-207.

4. Hopton AK, Curnoe S, Kanaan M, Macpherson H: Acupuncture in practice: mapping the providers, the patients and the settings in a national crosssectional survey. BMJ Open 2012, 2(1):e000456.

5. Robinson N, Lorenc A, Ding W, Jia J, Bovey M, Wang XM: Exploring practice characteristics and research priorities of practitioners of traditional acupuncture in China and the EU-A survey. J Ethnopharmacol 2012, 140(3):604-613.

6. Smith CA, Armour M, Betts D: Treatment of women's reproductive health conditions by Australian and New Zealand acupuncturists. Complement Ther Med 2014, 22(4):710-718.

7. Armour M, Ee CC, Hao J, Wilson TM, Yao SS, Smith CA: Acupuncture and acupressure for premenstrual syndrome. The Cochrane database of systematic reviews 2018, 8:CD005290.

8. Ormsby SM, Smith CA, Dahlen HG, Hay PJ: The feasibility of acupuncture as an adjunct intervention for antenatal depression: a pragmatic randomised controlled trial. Journal of Affective Disorders 2020, 275:82-93.

9. Smith CA, de Lacey S, Chapman M, Ratcliffe J, Norman RJ, Johnson NP, Boothroyd C, Fahey P: Effect of Acupuncture vs Sham Acupuncture on Live Births Among Women Undergoing In Vitro Fertilization: A Randomized Clinical Trial. JAMA 2018, 319(19):1990-1998.

10. Smith CA, Armour M, Dahlen HG: Acupuncture or acupressure for induction of labour. The Cochrane database of systematic reviews $2017,10: C D 002962$.

11. Armour M, Dahlen HG, Zhu X, Farquhar C, Smith CA: The role of treatment timing and mode of stimulation in the treatment of primary dysmenorrhea with acupuncture: An exploratory randomised controlled trial. PLoS One 2017, 12(7):e0180177.

12. Acupuncture Could Help With Period Pain, Study Reveals [https://. Accessed 25 Aug 2021.

13. Having acupuncture to increase IVF chances might be waste of time, study suggests [https://. Accessed 25 Aug 2021.

14. Verhoef MJ, Mulkins A, Carlson LE, Hilsden RJ, Kania A: Assessing the role of evidence in patients' evaluation of complementary therapies: a quality study. Integr Cancer Ther 2007, 6(4):345-353.

15. Bishop FL, Massey Y, Yardley L, Lewith GT: How patients choose acupuncturists: a mixed-methods project. J Altern Complement Med 2011, 17(1):19-25.

16. Ryan J: The use of evidence in acupuncture clinical practice. Australian journal of acupuncture and chinese medicine 2006, 1(1):19-23.

17. Ryan JD: Practice styles of beginner practitioners. J Altern Complement Med 2005, 11(3):477-482.

18. Armour M, Betts D, Roberts K, Armour S, Smith CA: The Role of Research in Guiding Treatment for Women's Health: A Qualitative Study of Traditional Chinese Medicine Acupuncturists. Int J Environ Res Public Health 2021, 18(2):834.

19. Robinson N, Bovey M, Lee JA, Zaslawski C, Tian P, Kim T-H, Alraek T, Bian Z-X, Lee MS, Birch S: How do acupuncture practitioners use pattern identification - An international web-based survey? European Journal of Integrative Medicine 2019, 32:100997.

20. Xue P, Zhan T, Yang G, Farella GM, Robinson N, Weihong Yang A, Liu J: Comparison of Chinese medicine higher education programs in China and five Western countries. Journal of Traditional Chinese Medical Sciences 2015, 2(4):227-234.

21. Anderson BJ, Kligler BE, Marantz PR, Gomes S, Casalaina WJ, Fuenmayor M, Ginsberg J, Greenough KA, Reznikova O, Saronson RL et al: Developing, Integrating, and Implementing Evidence-Informed Practice Curricula Throughout a Chinese Medicine Degree Program. J Altern Complement Med 2020, 26(6):463-472.

22. Bovey M, Lorenc A, Robinson N: Extent of acupuncture practice for infertility in the United Kingdom: experiences and perceptions of the practitioners. Fertil Steril 2010, 94(7):2569-2573.

23. Society for Acupuncture Research [https://www.acupunctureresearch.org/]. Accessed 25 Aug 2021.

24. Evidence Based Acupuncture [https://www.evidencebasedacupuncture.org/]. Accessed 25 Aug 2021.

25. Obstetrical Acupuncture Association [https://ob-acupuncture.com/]. Accessed 25 Aug 2021.

26. Sandelowski M: Whatever happened to qualitative description? Res Nurs Health 2000, 23(4):334-340.

27. Erlingsson C, Brysiewicz P: A hands-on guide to doing content analysis. African Journal of Emergency Medicine 2017, 7(3):93-99.

28. Ma Y, Dong M, Zhou K, Mita C, Liu J, Wayne PM: Publication Trends in Acupuncture Research: A 20-Year Bibliometric Analysis Based on PubMed. PLoS One 2016, 11(12):e0168123.

29. Barrington DJ, Robinson HJ, Wilson E, Hennegan J: Experiences of menstruation in high income countries: A systematic review, qualitative evidence synthesis and comparison to low- and middle-income countries. PLOS ONE 2021, 16(7):e0255001.

30. Hammerschlag R, Milley R, Colbert A, Weih J, Yohalem-llsley B, Mist S, Aickin M: Randomized controlled trials of acupuncture (1997-2007): an assessment of reporting quality with a CONSORT- and STRICTA-based instrument. Evid Based Complement Alternat Med $2011,2011$.

31. Birch S, Lee MS, Alraek T, Kim TH: Overview of Treatment Guidelines and Clinical Practical Guidelines That Recommend the Use of Acupuncture: A Bibliometric Analysis. J Altern Complement Med 2018, 24(8):752-769.

32. Birch S, Alraek T, Lee MS: Challenges for clinical practice guidelines in traditional medicines: The example of acupuncture. European Journal of Integrative Medicine 2016, 8(4):332-336.

33. Ee C, Levett K, Smith C, Armour M, Dahlen HG, Chopra P, Maroun P, Rao VS, Avard N, Grant S et al: Complementary medicines and therapies in clinical guidelines on pregnancy care: A systematic review. Women and Birth 2021.

34. Moore A, Komesaroff PA, O'Brien K, Xu H, Bensoussan A: Chinese Medicine in Australia. J Altern Complement Med 2016, 22(7):515-525.

35. Steel A, Leach M, Brosnan C, Ward V, Lloyd I: Naturopaths' mobilisation of knowledge and information in clinical practice: an international cross-sectional survey. BMC Complement Med Ther 2021, 21(1):205.

36. Full Circle Acupuncture Wellington [https://. Accessed 25 Aug 2021.

Page $9 / 10$ 
37. Maternity Acupuncture Mentoring and Peer Support [https://. Accessed 25 Aug 2021.

38. Betts D, Armour M, Robinson N: U.K. Support Network for Maternity Acupuncture: Survey of Acupuncturists on the Acupuncture (for Conception to) Childbirth Team. Med Acupunct 2019, 31(5):274-280.

39. American Board of Oriental Reproductive Medicine [https://aborm.org/]. Accessed 25 Aug 2021.

40. Hunter J, Armour M: Stop, Listen, and Learn: Using Mixed Methods to Add Value to Clinical Trials. J Evid Based Integr Med 2019, 24:2515690X19857073.

41. Roberts K, Betts D, Nie JB, Dowell A: Navigating the path: a qualitative exploration of New Zealand general practitioners' views on integration of care with acupuncturists. Acupunct Med 2021, 39(4):334-342.

42. Shelley BM, Sussman AL, Williams RL, Segal AR, Crabtree BF, Rios Net C: 'They don't ask me so I don't tell them': patient-clinician communication about traditional, complementary, and alternative medicine. Ann Fam Med 2009, 7(2):139-147.

43. Ee C, Templeman K, Grant S, Avard N, de Manincor M, Reath J, Hunter J: Informing the Model of Care for an Academic Integrative Health Care Center: A Qualitative Study of Primary Care Stakeholder Views. J Altern Complement Med 2020, 26(4):300-315.

44. García-Escamilla E, Rodríguez-Martín B: What can acupuncture bring to Westem medicine? The perspective of health professionals also trained in Traditional Chinese Medicine-based acupuncture. European Journal of Integrative Medicine 2017, 12:108-116.

45. Roberts K, Dowell A, Nie J-B: From research to practice: building bridges to enhance interprofessional communication between general practitioners and acupuncturists. Journal of Communication in Healthcare 2020, 13(3):234-244.

46. Lowe L-A, Betts D: Midwives' experiences of caring for women with antenatal anxiety and depression: A qualitative study with midwifery acupuncturists. New Zealand College of Midwives Journal 2021, 57.

47. Betts D, McMullan J, Walker L: The use of maternity acupuncture within a New Zealand public hospital: Integration within an outpatient clinic. New Zealand College of Midwives Journal 2016, 52:45-49.

48. Soliday E, Betts D: Treating Pain in Pregnancy with Acupuncture: Observational Study Results from a Free Clinic in New Zealand. J Acupunct Meridian Stud 2018, 11(1):25-30.

49. Smith CA, Collins CT, Levett KM, Armour M, Dahlen HG, Tan AL, Mesgarpour B: Acupuncture or acupressure for pain management during labour. Cochrane Database Syst Rev 2020, 2:CD009232.

50. Levett KM, Dahlen HG, Smith CA, Finlayson KW, Downe S, Girosi F: Cost analysis of the CTLB Study, a multitherapy antenatal education programme to reduce routine interventions in labour. BMJ Open 2018, 8(2):e017333.

51. Arentz S, Smith C, Redmond R, Abbott J, Armour M: A cross-sectional study of traditional Chinese medicine practitioner's knowledge, treatment strategies and integration of practice of chronic pelvic pain in women. BMC Complementary Medicine and Therapies 2021, 21(1):174.

52. Ben-Arye E, Scharf M, Frenkel M: How Should Complementary Practitioners and Physicians Communicate? A Cross-Sectional Study from Israel. The Journal of the American Board of Family Medicine 2007, 20(6):565-571. 